\title{
Transmission Line Galloping trajectory
}

Jiangshan Liu

School of North China Electric Power University, Baoding 071000, China.

ailrg103@qq.com

Keywords: Acceleration, Galloping, Trajectory

\begin{abstract}
Galloping is a process gradually formed. Initially, the line has a small-amplitude vibration around the equilibrium position. With the impact of wind energy negative air damping, the amplitude in the horizontal direction gradually reduced and vertical amplitude slowly increased. Thereby the path becomes larger and larger elliptical trajectory, and ultimately it is stable due to damping. That is, by using an acceleration sensor, respectively, we can measure galloping acceleration on the vertical and horizontal directions, which can be combined with the boundary conditions to determine the displacement in vertical and horizontal directions. Finally, we can fit the overall trajectory curve.
\end{abstract}

\section{Introduction}

Wire galloping will bring a lot of problems[1].For example, it can easily cause interphase short circuit, insulator arc-over,circuit trip,parts broken ,the tower collapsed and many major accidents.And it can bring huge economic losses and pose a huge damage to line security and stability. Working on line trajectory contributes to a deeper understanding of the mechanism of galloping and its effect on the mechanical properties of the transmission line. It has a certain reference value on the construction and operation of extra and ultra high voltage transmission line[2].

\section{The foundation of galloping trajectory[3].}

\section{Establishment of velocity and displacement formula.}

We assume that the observation point is moving in accordance with the elliptical trajectory. From the relationship between velocity $\mathrm{V}$, acceleration a,the displacement $\mathrm{S}$,

We can obtain that[4]:

In the $\mathrm{X}$ direction:

$$
\begin{gathered}
V(\mathrm{t})=V(x 0)+\int_{0}^{t} \frac{t}{0} a_{(t)} d t \\
S_{(\mathrm{t})}=S_{(x 0)}+\int_{0}^{t} \mathrm{~V}(t) d t \\
S(\mathrm{x} 0)=\int_{0}^{t}\left[V(x 0)+\int_{0}^{t} a_{(t)} d t\right] d t
\end{gathered}
$$

In the Y direction:

$$
\begin{gathered}
V(t)=V(y 0)+\int_{0}^{t} a_{(t)} d t \\
S(t)=S(y 0)+\int_{0}^{t} V_{(t)} d t \\
S_{(y 0)}+\int_{0}^{t}\left[V_{(y 0)}+\int_{0}^{t} a_{(t)} d t\right] d t
\end{gathered}
$$

Although the velocity and displacement movement of objects are in constant change, if the analog value can be changed into digital value, in a relatively short period the change of 
acceleration will be small. Therefore, we can calculate the part of the acceleration in a short time interval, then by summing the speed value can be obtained at any time.

In the $\mathrm{X}$ direction:

$$
\begin{gathered}
V\left(\mathrm{t}_{\mathrm{j}}\right)=V\left(\mathrm{x}_{0}\right)+\sum_{\mathrm{i}=1}^{\mathrm{j}} \mathrm{a}\left(\tau_{\mathrm{i}}\right) * \Delta \mathrm{t}_{\mathrm{i}} \\
S\left(\mathrm{t}_{\mathrm{j}}\right)=S\left(\mathrm{x}_{0}\right)+\sum_{\mathrm{i}=1}^{\mathrm{j}} \mathrm{V}\left(\tau_{\mathrm{i}}\right) * \Delta \mathrm{t}_{\mathrm{i}} \\
S\left(\mathrm{t}_{\mathrm{j}}\right)=S\left(\mathrm{x}_{0}\right)+\sum_{\mathrm{i}=1}^{\mathrm{j}}\left[\mathrm{V}\left(x_{0}\right)+\sum_{\mathrm{i}=1}^{\mathrm{j}} \mathrm{a}\left(\tau_{\mathrm{i}}\right) * \Delta \mathrm{t}_{\mathrm{i}}\right] * \Delta \mathrm{t}_{\mathrm{i}}
\end{gathered}
$$

In the Y direction:

$$
S\left(\mathrm{t}_{\mathrm{j}}\right)=S\left(\mathrm{y}_{0}\right)+\sum_{\mathrm{i}=1}^{\mathrm{j}}\left[\mathrm{V}\left(\mathrm{y}_{0}\right)+\sum_{\mathrm{i}=1}^{\mathrm{j}} \mathrm{a}\left(\tau_{\mathrm{i}}\right) * \Delta \mathrm{t}_{\mathrm{i}}\right] * \Delta \mathrm{t}_{\mathrm{i}}
$$

Therefore,

$$
S\left(\mathrm{t}_{\mathrm{j}}\right)=S\left(\mathrm{x}_{0}\right)+\sum_{\mathrm{i}=1}^{\mathrm{j}}\left[\mathrm{V}\left(\mathrm{x}_{0}\right)+\sum_{\mathrm{i}=1}^{\mathrm{j}} \mathrm{a}\left(\tau_{\mathrm{i}}\right) * \Delta \mathrm{t}_{\mathrm{i}}\right] * \Delta \mathrm{t}_{\mathrm{i}}+\mathrm{S}\left(\mathrm{y}_{0}\right)+\sum_{\mathrm{i}=1}^{\mathrm{j}}\left[\mathrm{V}\left(\mathrm{y}_{0}\right)+\sum_{\mathrm{i}=1}^{\mathrm{j}} \mathrm{a}\left(\tau_{\mathrm{i}}\right) * \Delta \mathrm{t}_{\mathrm{i}}\right] * \Delta \mathrm{t}_{\mathrm{i}}
$$

The formula above is the displacement of point moving in accordance with the elliptical trajectory.

Boundary conditions:

(1)When the vertical acceleration is the maximum and the horizontal acceleration is zero.

$$
S=S\left(\mathrm{x}_{0}\right)+\sum_{\mathrm{i}=1}^{\mathrm{j}}\left|\mathrm{V}\left(\mathrm{x}_{0}\right)+\sum_{\mathrm{i}=1}^{\mathrm{j}} \mathrm{a}\left(\tau_{\mathrm{i}}\right) * \Delta \mathrm{t}_{\mathrm{i}}\right| * \Delta \mathrm{t}_{\mathrm{i}}+S\left(\mathrm{y}_{0}\right)+\sum_{\mathrm{i}=1}^{\mathrm{j}} \sum_{\mathrm{i}=1}^{\mathrm{j}} \mathrm{a}\left(\tau_{\mathrm{i}}\right) * \Delta \mathrm{t}_{\mathrm{i}} * \Delta \mathrm{t}_{\mathrm{i}}
$$

(2)When the horizontal acceleration is the maximum and the vertical acceleration is zero.

$$
S=S\left(\mathrm{x}_{0}\right)+\sum_{\mathrm{i}=1}^{\mathrm{j}} \sum_{\mathrm{i}=1}^{\mathrm{j}} \mathrm{a}\left(\tau_{\mathrm{i}}\right) * \Delta \mathrm{t}_{\mathrm{i}} * \Delta \mathrm{t}_{\mathrm{i}}+S\left(\mathrm{y}_{0}\right)+\sum_{\mathrm{i}=1}^{\mathrm{j}}\left|\mathrm{V}\left(\mathrm{y}_{0}\right)+\sum_{\mathrm{i}=1}^{\mathrm{j}} \mathrm{a}\left(\tau_{\mathrm{i}}\right) * \Delta \mathrm{t}_{\mathrm{i}}\right| * \Delta \mathrm{t}_{\mathrm{i}}
$$

The boundary conditions and the initial position are different. In the boundary conditions, due to the point in the course of the campaign, the initial displacement $S$ is not zero. The initial position is the starting position, also called the equilibrium position, where the initial displacement $S$ is zero.

\section{The selection of initial position.}

According to the previous results, we can get the mathematical derivation of the elliptical trajectory with initial velocity and displacement. In the actual dancing monitoring process, initial velocity and initial displacement can not be obtained directly by acceleration sensor. Therefore, selecting the galloping initial position so as to avoid the presence of the initial velocity and initial displacement is one of the premise of galloping simulation.

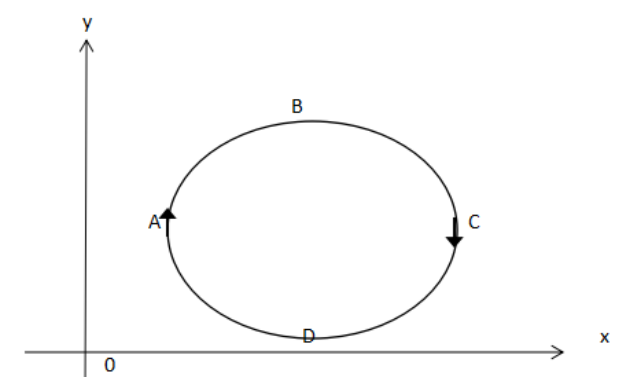

Making the transmission line as a particle, whose motion is in accordance with the elliptical trajectory. From point A to point D, according to physics we can know the relationship of acceleration and speed:

Point A: vertical acceleration is zero, horizontal acceleration reaches the maximum, vertical velocity reaches the maximum, horizontal velocity can be regarded as zero. 
Point B:horizontal acceleration is zero, vertical acceleration reaches the maximum, horizontal velocity reaches the maximum, vertical velocity can be regarded as zero.

Point C:vertical acceleration is zero, horizontal acceleration reaches the minimum, vertical velocity reaches the maximum, horizontal velocity can be regarded as zero.

Point D:horizontal acceleration is zero, vertical acceleration reaches the maximum, horizontal velocity reaches the maximum, vertical velocity can be regarded as zero.

From the previous analysis we can know, when the acceleration is the extreme value, the velocity of particle is equal to zero.Therefore, if the initial position is determined at the extreme value point of acceleration, it is able to meet the simulation requirement that the initial velocity is zero.

After the process of selecting the initial position, the formula of velocity and displacement can be modified as:

$$
\begin{gathered}
V\left(\mathrm{t}_{\mathrm{i}}\right)=\sum_{i}^{j} a\left(\tau_{i}\right) * \Delta t_{i} \\
S\left(\mathrm{t}_{\mathrm{j}}\right)=\sum_{i=1}^{j}\left[\sum_{i=1}^{j} a\left(\tau_{i}\right) * \Delta t_{i}\right]
\end{gathered}
$$

\section{Summary}

This paper is to establish simulation models, primarily to establish the mathematical expression of velocity, displacement and acceleration by the differential relationship. In the actual dancing monitoring process, initial velocity and initial displacement can not be obtained directly by acceleration sensor. Therefore, the selection of the initial position should be paid more attention to, which is one of the premise of galloping simulation.

\section{References}

[1]. C.B.Rawlins.Research on Vibration of Overhead Ground Wires[J].IEEE Transaction on Power Delivery,1988,p.769-775.

[2]. Gupta,S.,Wipf,T.,et al.Structural Failure Analysis of $345 \mathrm{kV}$ transmission Line[J].IEEE Transaction on Power Delivery,1994,p.894-903

[3]. Transmission line[J].International Society for Industrial Ecology,2001,p.973-978.

[4]. Huan Ren:Simulation and Monitoring System of Transmission Line Galloping Trajectory Based on Acceleration Sensor[D].Master degree.Chongqing University.China.2010.p.12. 